In No. Io (March $\mathrm{II}$ ) of the Comptes rendus $M$. Giacobini states that the comet is a round nebulous object of $20^{\prime \prime}$ diameter, having an eleventh-magnitude nucleus, anci, apparently, a tail in position-angle $180^{\circ}$.

SEARCh-ephemeris FOR COMET IgOO III. (Gincobini).In No. 4159 (March 7 ) of the Astronomische Nachrichten Herren Aboid and Scharbe publish a search-ephemeris, extending from March 5 to April 2, for comet I900 III. As the probable time of perihelion passage is very uncertain, they give three ephemerides, in which $T$ is taken as May 5 , June 8 , and July 13 respectively, June 8 being "onsidered the most probable. No perturbations have been taken into account, and as on March $1_{3}$ the calculated brightness was but 0.4 of that observed on February I5, 1901 , it is feared that the hopes of re-discovering this object are but small.

Solar Observations at Catania.-In No. 2, vol. xxxvi. of the Memorie della Società degli Spettroscopisti Italiani Prof. Ricco publishes the summarised results of the solar observations made at the Catania Observatory during the third and fourth quarters of 1906 . There was a marked decrease in the daily frequencies of spots, faculæ, and prominences during the fourth quarter as compared with the third, which, however, showed an increase in the daily frequency of all three phenomena on comparison with the results of the second quarter.

Intensificatron of "CONTRAst" BX means of a Polariscopr.--Some interesting suggestions concerning the in tensification of contrast in astronomical observations, by the employment of the polariscope, are made by Dr. Felix Biske in No. 2, vol. xxxvi. (February), of the Memorie della Società degli Spettroscopisti Italiani.

Dr. Biske points out that under certain conditions of the atmosphere and positions of the body observed it is possible to polarise the light received so that the ratio of the amount of light from the body to that of the sky is increased, thus rendering the details of the observed object more easily visible. It is suggested that by this means the observation of the corona whilst the sun is not eclipsed may be facilitated, and that comets, the light from which often shows a fair amount of polarisation, may be observed more easily. Similarly the planets Mercury and Venus and the moon may, under certain conditions, be observed when by the ordinary method this would be very difficult or impússible.

The Minor Planet (588) [1906 T.G.].--In No. 4155 of the Astronomische Nachrichten, Dr. Bidschof gives a new set of elements and an ephemeris for the minor planet (588), which, it will be remembered, is remarkable for its extraordinary aphelion distance, lying an astronomical unit beyond the mean distance of Jupiter. The elements are based upon observations made during 1906, and differ somewhat from those previously published by Dr. Berberich. This interesting object will be unfavourably situated for northern observers for several years, but it is to be hoped that the southern observatories will endeavour to keep it under observation.

The present magnitude of the planet is about $15 \cdot 0$, and it was re-observed by Prof. Wolf, in a position in fair accordance with Dr. Bidschof's ephemeris, on January 22.

Researches in Stellar Photometry.--Under the title "Researches in Stellar Photometry during the Years 1894 to 1906," made chiefly at the Yerkes Observatory, the Carnegie Iristitution of Washington has published a beautifully prepared and illustrated volume containing the results of Mr. J. A. Parkhurst's careful and systematic study of twelve variable stars having long periods and faint minima. The observations were carried out first with a 6 -inch reflector, then with a 12 -inch refractor, and finally with the 40-inch refractor of the Yerkes Observatory. Argelander's method of comparison was employed, and during the later years the comparison stars were carefully standardised with a pickering equalising wedge-photometer. In addition to the tabulated results giving the individual observations of the variable and of the comparison stars, $\mathrm{Mr}$. Parkhurst gives the complete light-curve, for the period of observation, of each variable, and a plate reproduction of a

NO. I 95I, voL. 75$]$ photograph showing the region surrounding each star; the majority of these are on the scale of $\mathrm{I} \mathrm{mm} .=13^{\prime \prime} \cdot 5$ (approx.). As an example of an attack on an important phase of the sidereal problem, the volume is almost unique in the wealth of detail it contains and the lavish manner in which the results are presented.

\section{MARSUPIALS OR CREODONTS?}

THE vexed question as to the real affinities of the marsupial-like carnivores of the Santa Cruz beds of Patagonia has once more been brought prominently to the front by the appearance of a memoir on their osteology and dentition in the fourth volume of the reports of the Princeton Expedition of $1896-9$ to Patagonia. In this memoir the author, Mr. W. J. Sinclair, takes up a very decided position, remarking that these so-called sparassodonts (as represented by Prothylacinus, Borhyæna, Amphiproviverra, \&c.) possess a number of characters either peculiar to marsupials or common to that group and only a few other orders. These, it is urged, will convince the reader that sparassodonts are true carnivorous marsupials, not worthy of even separate subordinal rank. $\mathrm{Mr}$. Sinclair goes, however, even farther than this, and considers himself justified in including the Patagonian carnivores in the same family group as the existing Tasmanian pouched wolf or thylacine, which he separates from the Dasyuridæ under the designation of Thylacinidæ (or Thylacynidæ). It is added that, "although there is sufficient similarity in structure to warrant placing the Patagonian and Tasmanian thylacines in the same family, it must not be inferred that the existing genus is the direct descendant of its extinct South American forerunners. The study of the group has failed to show a closer relationship than probable descent from a common Santa Cruz ancestor. While retaining the fundamental family characters, both lines have diverged, and in some respects the Santa Cruz forms are more advanced than the existing genus."

Among the structural features on which the author relies as evidence of the marsupial nature of the Patagonian fossils are the dental formula, the reduction in the number of successional cheek-teeth, the inflection of the angle of the lower jaw, a number of peculiarities in the conformation of the skull, and the perforation of the transverse process of the seventh cervical vertebra by the arterial canal. On the other hand, vacuities in the bony palate and epipubic (marsupial) bones, both of which are characteristic of most existing marsupials, are wanting.

As regards the dental formula of the cheek-teeth, this, in the opinion of Dr. J. L. Wortman (Amer, Journ. Sci., vol. xi., p. 336,1901 ) and the present writer, is identica in the sparassodonts, carnivorous marsupials, and creodonts, and is, therefore, of no importance, except to in dicate the mutual relationship of ail these three groups. By all zoologists of the present day it is, I believe, admitted that the reduction of the replacing teeth in modern marsupials to a single pair of premolars in each jaw is a secondary feature, so that the presence of a larger number of such teeth in the sparassodonts indicates the more primitive nature of those mammals, and one allying them to creodonts. Some of these sparassodonts differ, however, from all the more typical representatives of the latter group in having four, in place of three, pairs of upper incisor teeth, and thus resemble carnivorous marsupials; but since this feature is likewise regarded by $\mathrm{Dr}$. Wortman (op. cit., p. 335) as of secondary origin, it is no bar to the derivation of sparassodonts from creodonts, while it indicates that the latter are not likely to be the descendants of the former. As the author himself regards the presence of vacuities in the palate and the inflection of the lower iaw as being likewise secondary features in marsupials, all these lines of evidence point to the conclusion that creodonts are the most primitive of the three groups under consideration.

It follows from this, on the author's assumption that the Patagonian carnivores are thylacines, that palatal vacuities have been independently developed in several families of existing marsupials, and a similar argument will hold good with regard to the reduction of the 
successional cheek-teeth. Such independent developments seem, however, in the highest degree improbable.

The fact that in the existing thylacine the epipubic bones do not ossify may perhaps be held to indicate that a similar condition obtained in the Miocene sparassodonts, although such a loss is improbable in these early forms, more especially as one of them is considered to have been partially arboreal. Be this as it may, it is quite clear (unless we again admit a series of independent developments) that the sparassodonts cannot be regarded as belonging to a grade of marsupials in which these bones had not yet been evolved, because we find them fully developed in the Oligocene opossums.

The most important argument of all against the marsupial nature of these Patagonian carnivores is, however, one derived from the nature of the enamel of their teeth, which does not appear to have come under the author's notice. According to the observations of Mr. C. S. Tomes (Proc. Zool. Soc. London, I906, p. 45) the enamel of the sparassodont teeth is histologically identical with that of creodonts and modern carnivores, and quite unlike that of all marsupials.

Seeing, then, that sparassodonts, which are later in age than certain undoubted marsupials, differ from existing carnivorous marsupials as a whole in the minute structure of their dental enamel, by the lack of epipubic bones, the absence of unossified spaces in the floor of the skull, and apparently by the larger number of successional premolars, it seems improbable that they are really members of that group. On the other hand, they resemble creodonts in their complete palates, in the absence of epipubic bones, and to a great degree as regards the replacement of the cheek-teeth, while it is highly probable that many of the cranial characters referred to as being marsupial may really be primitive ones. The one essentially marsupial feature is the presence, in some cases, of four pairs of upper incisors.

On the whole, therefore, it seems advisable to regard the Patagonian carnivores as creodonts showing a tendency (it may or may not be parallelism) towards the marsupial type. That creodonts, sparassodonts, and carnivorous marsupials are, however, related groups, and that the former are not improbably the oldest and most primitive of all known mammals (perhaps directly descended in "Gondwanaland" from anomodont reptiles), appears almost certain. And it may further be suggested that these early creodonts have developed in one direction towards the sparassodont type, in a second towards the carnivorous marsupials, while in a third line they have developed into the modern Carnivora. Beyond this it seems at present impossible to go.

It should be added that the present writer was at one time of opinion that sparassodonts were marsupials.

R. L.

\section{THE GODS OF HEALING OF THE EGYPTIANS AND GREEKS.}

D R. R. CATON recently delivered a short course of lectures on the above subject in connection with the Institute of Archæology at the University of Liverpool. After referring to the works on medicine written by Athosis, the son of Menes, and also by the Pharaohs, Usaphais and Semti in very early times, he described briefly the cults of Isis, Serapis, Thoth, and I-em-hotep, and gave a short account of the temples in which the work of healing took place. Of these, quite the most important was the temple of I-em-hotep at Memphis. All these shrines of healing are destroyed, excepting the small temple of I-em-hotep on the island of Philæ. Dr. Caton referred to the large number of medicinal agents used by the Egyptians, and to the practice of incubation or temple sleep. In the temples of Isis and Serapis, and probably in the more important shrines of I-em-hotep, the sick slept in or adjacent to the temples, in the belief that the god would manifest himself to them or speak to them in dream or vision, and suggest the method of cure. Such dreams or visions were interpreted by the priest, and the treatment adopted was supposed to be founded in accordance with them. Sometimes no dream was vouchsafed, or no interpretation could be drawn from it bearing on the disease; in that case the priest did the dreaming. The priests of I-em-hotep had also to do with the embalming of the body, and, partly through this, they acquired a considerable knowledge of anatomy, and learned certain facts regarding the circulation of the blood. Some of the medical papyri contain remarkable details as to the bloodvessels and the movement of the blood; probably the Greeks obtained from them all the knowledge they possessed on this subject.

In Greece and Magna Græcia various gods and demigods were supposed to possess medical powers. Men Karon at Laodicea was a health god much in vogue in Asia Minor, and a large medical school was associated with his temple.

Apollo, Amynos, Asklepios, Hygeia, Amphiaraus, Trophonios, Aphrodite, and the Chthonic deities Pluto, Demeter, Persephone, and others of lesser importance were eminent for their health-giving efficacy in Greece. Of these, the cult of Asklepios was by far the most important. At numerous splendid temples, rich with the finest products of Greek art, the worship of the god and the cure of the sick were carried on for centuries.

Epidaurus was perhaps the most important of these shrines; it was a centre from which the cult was disseminated through other parts of Greece and the colonies. Trained priests, and also the sacred serpents, which were believed to be the incarnation of the god, were sent thence to carry on the work of healing in such places as Athens, Corinth, Delphi, Pergamon, Cnidos, Rhodes, Cos, and many other cities.

In all, incuhation was the initial step and the guide as to treatment. Probably the people would have had no confidence in the methods used but for the belief that the god himself had suggested them; even the priests themselves may in part have been believers. Many of the priests were physicians, who in the corurse of ages compiled much valuable information; they possessed useful methods of treatment in regard to rest, to diet, to the remedial use of exercise and of baths, and medicines. The ritual was beautiful and impressive, and their practice seems to have been humane in all respects except one. The god and his priests must have no dealings with death or with birth. If either were impending, the unhappr patient was at once expelled from the holy precinct. Not until the time of the Antonines were the special " houses of Birth and of Death" provided, external to the precinct for these two classes of sufferers.

At $\operatorname{Cos}$ the influence of Hippocrates seems to have been directed always towards the effacement of superstition and the founding of medicine on truth and fact alone. His influence seems to have had no effect as regards the practice of incubation, for it continued through Pagan and into Christian times.

As the East was Christianised the cult of Asklepios was the last to disappear, but the healing went on in the same manner (excepting that the sacred serpents seem to have vanished). The Panagia, or a Christian saint, took the place of Asklepios, and incubation went on unchanged. The practice spread over large parts of Europe, and was even to be found in England during the Dark Ages.

It still exists on many of the islands and on some of the shores of the eastern Mediterranean. Details of the ancient and modern practice of incubation are to be found in the writings of Dr. Rouse and Miss Hamilton, who have both devoted close attention to this curious usage.

An interesting feature of the life of these ancient health resorts was the provision made for the entertainment and amusement of the sick visitors. A great open-air theatre was always at their disposal, where the works of the Greek dramatists would wile away many an hour of weariness and languor.

In later times an Odeon, or music-hall, was sometimes provided. The races of the stadium and the exercises of the gymnasium and palxstra would be good for many of the youthful convalescents to take part in, and amusing for others to witness. The health temples were usually placed in elevated situations, where pure mountain breezes would invigorate the visitant, and pure, fresh water was

No. I 95 I, VOI. 75] 